\title{
THERMOSTABILITY CHARACTERISTICS OF GLUCOSEPHOSPHATE AND TRIOSEPHOSPHATE ISOMERASE IN ERYTHROCYTES FROM SEVERAL SPECIES
}

\author{
J. M. NAIDU*, T. R. TURner $\dagger$ and H. W. Mohrenweiser \\ Department of Human Genetics, Box 015, University of Michigan Medical School, Ann Arbor, \\ MI 48109-0010, USA (Telephone: (313) 764-4434)
}

(Received 2 March 1984)

\begin{abstract}
Significant differences in the thermostability of both glucosephosphate and triosephosphate isomerase were noted among a series of six primate and five nonprimate species.

2. The enzyme structural differences among species, as assessed by thermostability profiling, was greater than expected from electrophoretic mobility patterns.

3. Microheterogeneity of GPI, i.e. differences in thermostability within a species that are not detectable by electrophoresis, was detected in two primate species.

4. Major differences in the levels of erythrocyte enzyme activity were observed with human and cow differing by 18-fold for TPI and baboon and cow differing by seven-fold in GPI activity.
\end{abstract}

\section{INTRODUCTION}

Comparative enzymology has been a useful approach to the study of the role of specific amino acid residues in enzyme mechanisms, the importance of enzymes in physiological functions and evolutionary relationships among species. These studies have generally centered on "recently" duplicated loci but have at times also focused on more divergent loci (Gracy, 1982; Hewett-Emmett et al., 1982; Li, 1983; Tashian et al., 1983; Wheat and Goldberg, 1983). Triosephosphate isomerase (TPI; EC 5.3.1.1) and glucosephosphate isomerase (GPI; EC 5.3.1.9) are enzymes which share many common mechanistic features and some structural similarities, but exhibit significant differences in levels of genetic variation. Thus they provide the basis for potentially interesting comparisons of divergent loci.

GPI and TPI catalyze reversible aldose-ketose reactions via similar mechanisms (Noltmann, 1972) involving a histidine and a glutamic acid residue at the catalytic center (Achari et al., 1981; Alber et al., 1981). The active site of GPI also involves a lysine (Lu et al., 1981; Palmieri et al., 1982) and probably an arginine residue (Pullan et al., 1983). Electron density maps of the two enzymes suggest similarities in structural features (Steinberg et al., 1981) and similarities are noted in the active site peptides of the two enzymes (Hartman and Gracy, 1973; Gibson et al., 1983; Gracy, 1982). Both enzymes are products of single structural loci in animal species (Womack, 1982), although a second TPI isozyme is observed in proliferating cells from higher primates (Decker and Mohrenweiser, 1981). This second isozyme is the

\footnotetext{
*Present address: Department of Anthropology, Andhra University, Waltair, India 530003

†Present address: Department of Anthropology, University of Wisconsin-Milwaukee, Milwaukee, WI 53201, USA.
}

product of the same structural locus as the constitutive isozyme (Decker and Mohrenweiser, 1981). Cell division or tissue specific isozymes of GPI have not been observed for animal species (Kester et al., 1977; Rogers et al., 1980). Both enzymes have dimeric structures although the subunit molecular weight of GPI (63,000 daltons) (Gracy, 1982) is more than twice the molecular weight of the TPI subunit $(25,000$ daltons) (Corran and Waley, 1975). Given the structural and mechanistic similarities of the enzymes, it has been suggested that they are derived from a common ancestral protein (Sternberg et al., 1981).

Many mobility differences are noted when comparing GPI from various animal species (Scopes, 1968) and electrophoretic variants of GPI are noted, often as polymorphisms, within many animal species (Richkind and Richkind, 1978; Sandberg, 1973; VandeBerg and Stone, 1978). Variants with frequencies approaching $1 \%$ are noted in many human populations-also (Omoto and Blake, 1972). In contrast, electrophoretic mobility variants of TPI are rare in human populations (Neel et al., 1980a,b) as are structural variants within other animal species (Gracy, 1982). Also mobility differences for TPI among animal species are apparently minimal (Snapka et al., 1974). For example, the mobility of TPI in five nonhuman primate species is identical to the mobility of the enzyme from humans (Turner $e t$ al., 1984). The sequence data available for TPI suggests a slow rate of evolution for this enzyme (Dayhoff, 1978). Although similar sequence data are not available for GPI, the extent of electrophoretic variation within and between species would seem to suggest that GPI is more tolerant of amino acid substitutions and consequently significant species differences in GPI structure may be expected when similar comparisons are completed.

The absence of either TPI or GPI results in a metabolically significant genetic disease. GPI deficiency is the third most prevalent cause of hemo- 

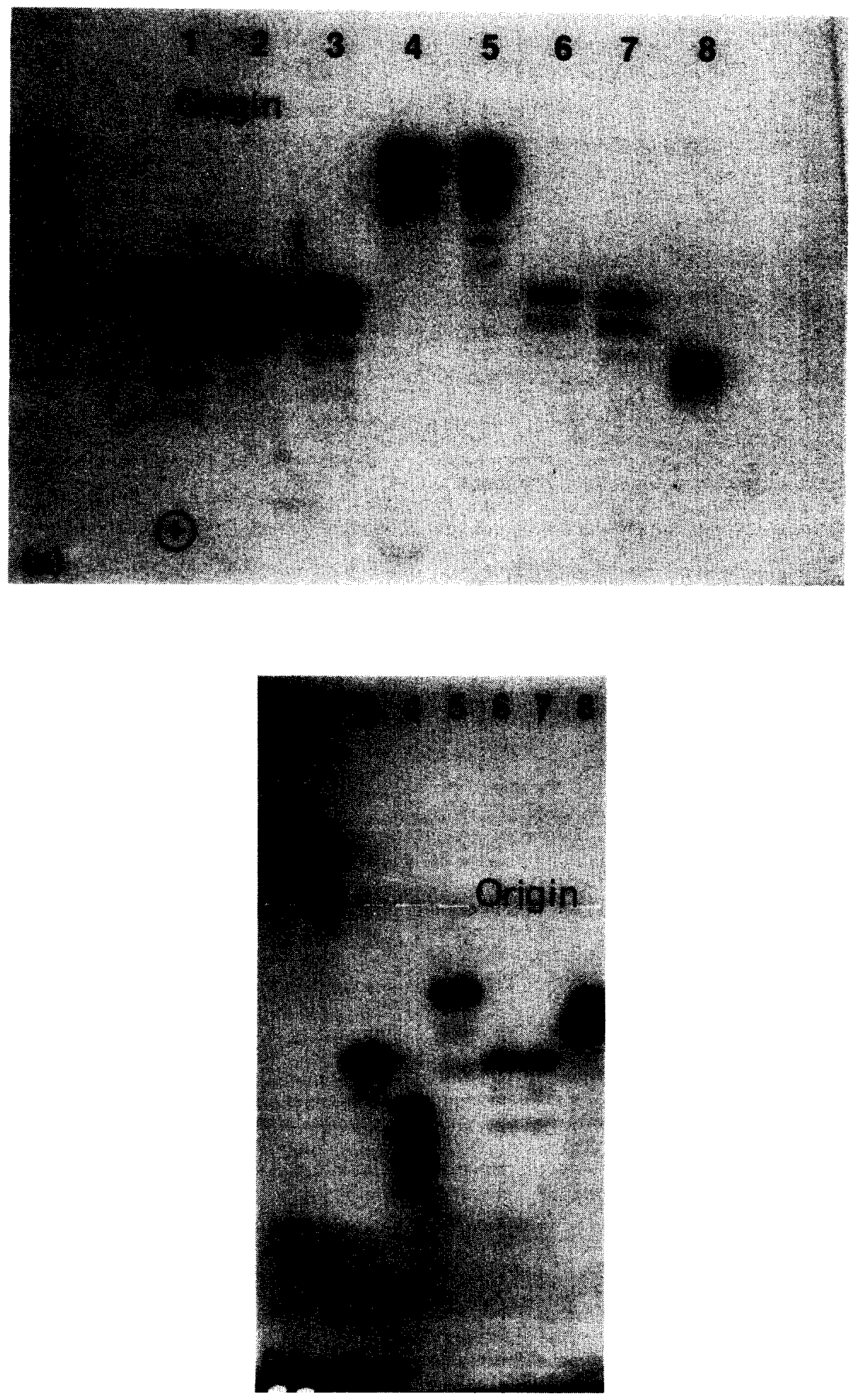

Fig. 1. Electrophoretic pattern of TPI and GPI isozymes in several species. The isozyme profile of TPI is in (A) and the profile of GPI isozymes is in (B). Lane 1, human; lane 2, chimp; lane 3, patas; lane 4, rabbit; lane 5, dog; lane 6 , cow; lane 7 , sheep; lane 8 , chicken. 
lytic anemia in humans (Arnold, 1979; Kahn et al., 1979). By contrast, homozygotes for TPI deficiency are rare but the condition is considered the most severe glycolytic enzyme deficiency, usually resulting in death before the age of four years (Kahn et al., 1979; Vives-Corrons et al., 1978). This low observed frequency of homozygotes is in contrast to the high frequency for a TPI null allele observed in the US Black population (Mohrenweiser and Fielek, 1982; Mohrenweiser, 1983).

This paper will examine the extent of structural variation, as assessed by thermostability, in these two enzymes among primate species for which significant differences in levels of erythrocyte enzyme activity had been previously observed. It will also report on similar characteristics of these erythrocyte enzymes in several nonprimate species and again contrast differences in thermostability with electrophoretic mobility and erythrocyte enzyme activity patterns.

\section{MATERIALS AND METHODS}

Blood was drawn in ACD vacutainers, the cells were washed three times with saline plus $0.1 \%$ mercaptoethanol and stored at $-90^{\circ} \mathrm{C}$ (or in liquid $\mathrm{N}_{2}$ ) as packed cells. Hemolysates were prepared as previously described (Fielek and Mohrenweiser, 1979). Enzyme assays, thermolability, electrophoresis and immunological studies were as described previously (Satoh and Mohrenweiser, 1978; Asakawa and Mohrenweiser, 1982; Mohrenweiser and Fielek, 1982). The primate species (Papio anubis, baboon; Macaca mulatta, rhesus; Pan paniscus, chimp: Cercopithecus aethiops, vervet; Erythrocebus patas, patas) have been described by Turner $e t$ al., 1984). The samples from the other species were obtained from healthy animals maintained by the University of Michigan Laboratory Animal Care Unit except the bovine samples which were obtained through the Department of Animal Science at Michigan State University. Blood from three or four individual animals of each species were used throughout the study. All incubations and assays were done in duplicate. The chicken antihuman TPI sera was a gift from Drs Eber and Krietsch of the University of Munich.

\section{RESULTS}

\section{Electrophoretic}

Previous analyses (Turner et al., 1984) have shown that the electrophoretic mobility of TPI in the five nonhuman primates is identical to the mobility of the isozyme from humans while for GPI the mobility of the enzyme from chimp and human differs from the mobility of the enzyme in the other four species.
Among the nonprimate species, the mobility of TPI from sheep and cow is similar and does not differ from the mobility of the primate isozyme (Fig. 1(A)). The isozymes from rabbit and dog migrate cathodal, relative to the primate isozyme, and also apparently do not differ from each other. The migration of the chicken isozyme is anodal to the human isozyme. The deamidation bands associated with the labile asparagine residues of the human (Gracy and Yuan, 1980) and rabbit (Corran and Waley, 1975) isozymes are seen in all species except the chicken where it is known that a lysine has replaced Asp 15 (Banner et al., 1975).

Seven electrophoretic mobility classes are observed for GPI (Fig. 1(B)). Only the isozymes from humans and chimps exhibit cathodal mobility at $\mathrm{pH}$ 8.6. The isozymes from the other species exhibit anodal mobility and with the exception of the cow and sheep isozymes, each has a unique mobility. In contrast to previous electrophoretic studies with polyacrylamide as a support (Turner et al., 1984), the GPI isozymes from human and chimp exhibited slightly different mobilities when the electrophoresis was conducted at pH 8.6 with hydrolyzed starch as the support.

\section{Enzymatic activity}

The levels of enzymatic activity in erythrocytes of the different species, expressed as units per g hemoglobin, are in Table 1. As previously reported, the human has the highest TPI activity of the primate species, with the nonhuman primates having approximately $30-50 \%$ the human activity. The erythrocyte TPI activity for $\operatorname{dog}(59 \%)$ and rabbit $(42 \%)$ and chicken $(32 \%)$ is also in the range observed in erythrocytes from nonhuman primates. The TPI activity in bovine and sheep erythrocytes is the lowest of any of the species with the activity in bovine erythrocytes being only $6 \%$ the activity observed in human erythrocytes.

As previously observed, the order for GPI activity among the primates is very different from that observed for TPI activity. The baboon has the highest GPI activity while the other four nonhuman primates have $50-70 \%$ of the baboon activity. In contrast to TPI, human erythrocytes have the lowest GPI activity (30\% of baboon) among the primates. The rabbit erythrocyte GPI activity is equal to that of the baboon while the dog GPI activity is only $33 \%$ of baboon activity. Chicken and the cow/sheep pair

Table 1. Activity of TPI and GPI in erythrocytes of several species

\begin{tabular}{|c|c|c|c|c|c|}
\hline \multicolumn{3}{|c|}{ TPI } & \multicolumn{2}{|c|}{ GPI } & \\
\hline Species & $\begin{array}{c}\text { Activity } \\
\text { (units } \pm \text { SD) } \times 10^{-2}\end{array}$ & $\%$ & Species & $\begin{array}{c}\text { Activity } \\
\text { (units } \pm S D \text { ) }\end{array}$ & $\%$ \\
\hline 1. human & $1617 \pm 132$ & 100 & 1. baboon & $11,060 \pm 1055$ & 100 \\
\hline 2. $\operatorname{dog}$ & $994 \pm 183$ & 59 & 2. rabbit & $11,020 \pm 680$ & 99 \\
\hline 3. patas & $875 \pm 87$ & 54 & 3. patas & $9800 \pm 740$ & 88 \\
\hline 4. baboon & $720 \pm 71$ & 44 & 4. rhesus & $7830 \pm 1005$ & 71 \\
\hline 5. rabbit & $676 \pm 119$ & 42 & 5. vervet & $6150 \pm 615$ & 56 \\
\hline 6. chimp & $572 \pm 84$ & 35 & 6. chimp & $5710 \pm 230$ & 52 \\
\hline 7. rhesus & $527 \pm 117$ & 33 & 7. $\operatorname{dog}$ & $3670 \pm 740$ & 33 \\
\hline 8. chicken & $517 \pm 76$ & 32 & 8. human & $3330 \pm 560$ & 30 \\
\hline 9. vervet & $447 \pm 80$ & 27 & 9. chicken & $2469 \pm 85$ & 22 \\
\hline 10. sheep & $325 \pm 71$ & 20 & 10. sheep & $1640 \pm 405$ & 15 \\
\hline 11. cow & $97 \pm 24$ & 6 & 11. cow & $1510 \pm 155$ & 14 \\
\hline
\end{tabular}

${ }^{a}$ Expressed as percent of activity in highest activity species. 


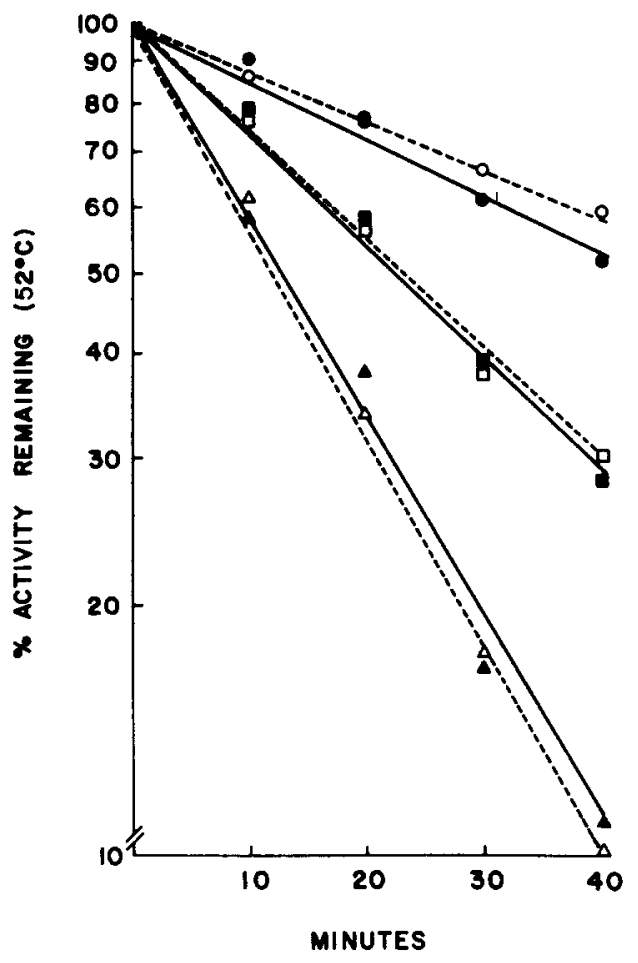

Fig. 2. Thermostability of GPI in chimps and patas. Open symbols/dotted lines are patas; filled symbols/solid lines are chimps.

have only 14 and $15 \%$ of the highest GPI activity and as with TPI, rank lowest in enzymatic activity.

\section{Thermostability}

The thermostability differences observed are of two types. The first is within species variation, as observed for GPI among chimps and also patas (Fig. 2). Three thermostability classes (stable, intermediate, labile) are observed in both species. These differences in thermostability are observed when the hemolysates are dialyzed prior to the heating step, and mixing of hemolysates from the different groups, prior to heating, results in generation of an intermediate stability profile. Both of these results are expected if the lability is associated with differences in the enzyme structure rather than a factor conferring stability/lability to the enzyme. Samples from eight chimps had the thermostable phenotype while six had the intermediate and two the labile phenotype. The distribution was ten stable, three intermediate and three labile among the patas samples. Although heritability data are not available, the data are consistent with the existence of two allelic forms of GPI in each species with the intermediate group being the heterozygotes. Similar intraspecies heterogeneity was not detected for TPI for these or for the other species.

The results of the thermostability comparisons among species are summarized in Table 2 . Three thermostability classes are observed for TPI among the six primates species with the human enzyme being most stable $\left(t_{1 / 2}\right.$ of $37 \mathrm{~min}$ at $\left.58^{\circ} \mathrm{C}\right)$, followed by the enzyme from chimp erythrocytes $\left(t_{1 / 2} 21 \mathrm{~min}\right.$ at $\left.58^{\circ} \mathrm{C}\right)$. The enzymes from the other four species were similar with $t_{1 / 2}$ 's $\left(52^{\circ} \mathrm{C}\right)$ of $13-16 \mathrm{~min}$ and obviously much more labile than the human and chimp isozymes. The half-life of this labile isozyme could not be measured at $58^{\circ} \mathrm{C}$. The thermostability of the TPI enzyme from the five nonprimate species all differed from each other, including a difference between the cow and sheep isozymes which were electrophoretically similar. The lability of the enzyme from the nonprimate species is intermediate to that observed for the higher and lower primate groups.

The comparison of the thermostability of the GPI isozyme is more complex, given the microheterogeneity within two of the primate species, although several conclusions are apparent. GPI from baboon, rhesus and vervet differ by amino acid substitutions which are electrophoretically silent. Similarly the enzyme from cow and sheep possess identical electrophoretic mobility but display different inactivation profiles. Also the isozymes from the various divergent species which are electrophoretically different have very different thermostabilities. The similarity of the inactivation profile for the baboon and rhesus isozyme to the most labile of the patas and the chimp isozymes is also noted. It should be noted also that, as with the levels of enzymatic activity, the rank order for thermostability is very different between the two enzymes and also differs from the rank order for activity.

\section{Immunoinactivation}

The 18-fold difference in the level of erythrocyte TPI activity between bovine and human and, to a lesser extent, the differences among the primates could reflect either a large difference in kinetic properties between the isozymes or a difference in the level of enzymatically active TPI protein in the erythrocyte. Given the similarities in the kinetic properties of TPI from various species (Corran and Waley, 1975: Banner et al., 1975; Eber and Krietsch, 1980), differences in kinetic properties in the enzyme from these species were not expected. Therefore, assuming similar immunoreactivities, the amount of antisera required to inactivate a unit of enzyme activity is a relative measure of the quantity of enzyme protein and therefore is a measure of relative specific activity.

Table 2. Thermostability of erythrocyte TPI and GPI in several species

\begin{tabular}{|c|c|c|c|c|}
\hline & & & & \\
\hline & & & & \\
\hline & $58 \mathrm{C}$ & $52 \mathrm{C}$ & 520 & $49 C$ \\
\hline human & 37 & -3 & 19 & \\
\hline chimp (1) & 21 & $\cdots$ & 46 & \\
\hline chimp (2) & $-\cdot$ & $\cdots$ & 23 & \\
\hline chimp (3) & - & 一. & 14 & \\
\hline baboon & $\ldots$ & 15 & 11 & -60 \\
\hline rhesus & - & 13 & 10 & 44 \\
\hline patas (1) & - & 16 & 47 & \\
\hline patas (2) &.$- \cdot$ & $-\cdots$ & 23 & \\
\hline patas (3) & $\cdots$ & -- & 13 & $\cdots$ \\
\hline vervet & -- & 13 & $\sim 5$ & 23 \\
\hline cow & $-\ldots$. & 41 & $\sim 3$ & 18 \\
\hline sheep & - & 50 & & 12 \\
\hline rabbit & 13 & $\cdots$ & 19 & \\
\hline $\operatorname{dog}$ & 9 & -60 & 15 & \\
\hline chicken & 8 & $>90$ & 60 & \\
\hline
\end{tabular}

Temperatures at which half lives could not be calculated. 


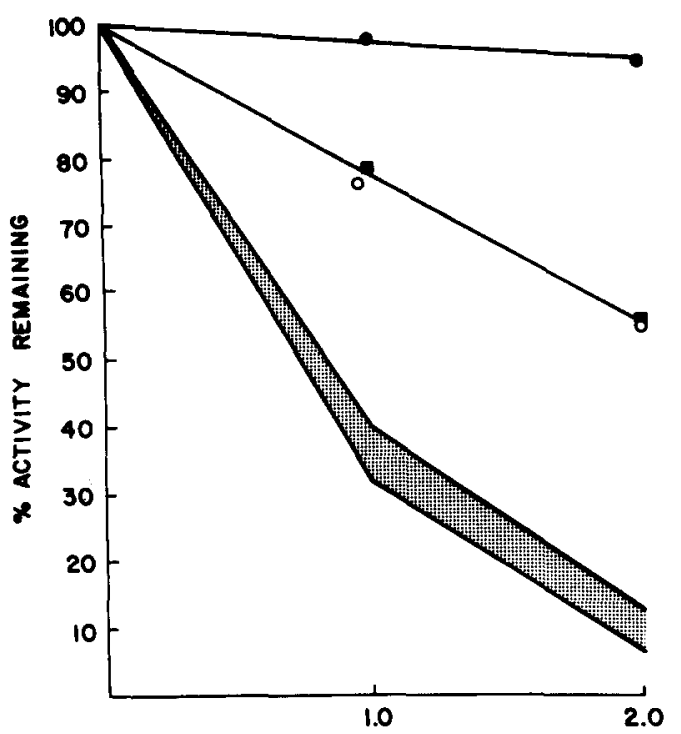

HI ANTISERA

Fig. 3. Immunoinactivation profile of TPI in hemolysates from several species. All samples were adjusted to a constant level of enzyme activity. Incubation and assay conditions are described in Mohrenweiser and Fielek (1982). (O) Chicken; $(O)$ sheep; $(\mathbb{D})$ cow. The range for all individuals for the remaining eight species is indicated by the stippled area.

Similar immunoinactivation profiles were observed for all of the primates plus the enzyme from the rabbit and dog. The profile for the sheep and cow enzyme is very different where $1 \mu l$ of antisera inactivates only $30 \%$ of the enzyme activity rather than the $70 \%$ of the activity as observed for the other species (Fig. 3). The absence of inactivation of the chicken enzyme is as expected and is a clear indication of the specificity of the immunoinactivation.

\section{DISCUSSION}

The levels of erythrocyte GPI activity in the nonprimate species is similar to previous reports (Smith et al., 1965). Similar comparative data have not been generally available for TPI. With the exception of the sheep, cow and chicken, which have the lowest activity for both enzymes, expressed as activity per $g$ hemoglobin, no consistency in rank order or percent of maximum activity is noted between the enzymes. Previous data indicate that the low enzyme activity in sheep, cow and chicken erythrocytes is not simply a reflection of differences in the hemoglobin concentration in that they have relatively higher activity levels for several other glycolytic enzymes when similar species comparisons are made (Agar et al., 1975; Agar and Smith, 1974; Smith et al., 1965; Smith and Kiefer, 1973). It should be noted that the level of TPI activity in bovine erythrocytes is very similar to the activity reported for erythrocytes from TPI deficient newborns that exhibit severe hemolytic anemia (Kahn et al., 1979; Vives-Corrons et al., 1978).

The differences in thermostability of GPI within the chimp and patas groups are similar to the micro- heterogeneity observed within electromorphs at many loci in other organisms (Singh et al., 1975; Thorig et al., 1975; Beckenbach and Prakash, 1975) including several human GPI isozymes (Satoh and Mohrenweiser, 1979). The retention of the differences following dialysis, the intermediate stability in mixing experiments and the absence of similar heterogeneity for TPI suggests that the thermostability difference among animals within these two species reflects differences in GPI structure resulting from "silent" amino acid substitutions. Three electrophoretically identifiable GPI isozymes are observed among the six primate species and seven isozymes are detectable among the 11 species. Addition of the thermostability differences to the mobility variants increases the isozymes (including the allelic isozymes in both chimps and patas) observed in the primates to eight and among all of the species studied to 13. That is, each species has a unique GPI isozyme.

The TPI thermostability differences among the primates are in contrast to the similarities in electrophoretic mobility. The thermostability data suggest at least 3 isozymes (human, chimp and the lower primates group) which differ from each other by "silent" substitutions (or pairs of compensating substitutions). Again as with GPI, each of the electrophoretically distinct TPI isozymes has a unique thermostability profile. Inclusion of the thermostability data with the electrophoretic mobility data increases the number of TPI isozymes among the primate species from one to at least three. Combining the data from both techniques increases the number of TPI isozymes among the 11 species from three to eight. Thus inclusion of thermostability studies with electrophoretic analysis more than doubles the number of isozymes detected, observations consistent with population screening studies (Mohrenweiser and Neel, 1981) and theoretical considerations of the ratio of charged and uncharged amino acids. The thermostability data, although limited, suggest that a larger portion of the amino acid substitutions are electrophoretically neutral in TPI than for GPI, a suggestion not inconsistent with the previously observed heterogeneity.

Previous data have shown that the specific activity of TPI is similar in very diverse species (ArtavanisTrakonas and Harris, 1980; Eber and Krietsch, 1980; Putman et al., 1972), thus, the similarity of the immunoinactivation profile for the human and rabbit enzyme is consistent with the previous observations. The data are also consistent with a similar specific activity for the enzyme from the other primate species as well as the enzyme from dog. This data would indicate that the differences in levels of enzymatic activity among these species reflect differences in the quantity of enzyme protein in the cell. The cow/sheep data suggest that the specific activity of TPI from these species is only $30 \%$ of that observed for the other species in this study. Although this observation is consistent with the very reduced levels of erythrocyte enzyme activity, it can explain only about $20 \%$ of the reduced activity. The possibility that the profile differences are a measure of immunological relatedness cannot be excluded at this time. The differences in enzyme activity among the other species, given the constancy of the specific activity, are best explained 
by differences in levels of enzyme proteins. These could reflect either differences in rates of synthesis or rates of degradation, the latter having a very pronounced effect in erythrocytes because of the absence of protein synthesis in these cells.

It is apparent that significant structural differences exist among these species for both GPI and TPI. The number of differences observed for TPI are somewhat surprising given the minimal electrophoretic variation previously observed for this isozyme as well as the slow rate of evolutionary change at this locus. By contrast, the variation in GPI structure, including the microheterogeneity, is almost expected given previously reported variation with this enzyme. It would seem apparent that minimal amino acid substitutions, including silent substitutions, can result in measurable structural alterations, some of which may be of physiological significance, as refiected in differences in levels of erythrocyte enzyme activity.

Acknowledgements - Financial support was derived from Contract EY-77-C-02-2828 from the Department of Energy (H.W.M.), NIH Training Grant, T-32GM07123 (T.R.T.) and a scholarship from the Government of India, Ministry of Education (J.M.N.). The assistance and helpful discussions of K. H. Wurzinger and S. Fielek are appreciated.

\section{REFERENCES}

Achari A., Marshal S. E., Muirhead H., Paimieri R. H, and Noltmann E. A. (1981) Glucose-6-phosphate isomerase. Phil. Trans. R. Soc. Lond. B. 293, 145-157.

Agar N. S., Gruca M. A., Dunbar J. and Harley J. D. (1975) Red cell enzymes I. Glycolytic enzymes and reduction of glutathione in bovine red blood cells. Comp. Biochem. Physiol. 51B, 463-466.

Agar N. S. and Smith J. E. (1974) Enzymes and glycolytic intermediates in the rabbit erythrocytes. Enzyme 17, $205-209$.

Alber T., Banner D. W., Bloomer A. C., Petsko G. A., Phillips D., Rivers P. S. and Wilson I. A. (1981) On the three dimensional structure and catalytic mechanism of triosephosphate isomerase. Phil. Trans. R. Soc. Lond. B 293, 159-171.

Arnold H. (1979) Inherited glucosephosphate isomerase deficiency-A review of known variants and some aspects of the pathomechanism of the deficiency. Blut 39, 405-417.

Artavanis-Tsakonas S. and Harris J. I. (1980) Primary structure of triosephosphate isomerase from Bacillus stearothermophilus. Eur. J. Biochem. 108, 599-611.

Asakawa J. and Mohrenweiser H. W. (1982) Characterization of two new electrophoretic variants of human triosephosphate isomerase: Stability, kinetic and immunological properties. Biochem. Genet. 20, 59-76.

Banner D. W., Bloomer A. C., Petsko G. A., Phillips D. C., Pogson C. I., Wilson I. A., Corran P. H., Furth A. J., Milman J. D., Offord R. E., Priddle J. D. and Waley S. G. (1975) Structure of chicken muscle triosephosphate isomerase determined crystallographically at $2.5 \AA$ resolution using amino acid sequence data. Nature, Lond. 255i, 9-614.

Beckenbach A. T. and Prakash, S. (1977) Examination of allelic variation at the hexokinase loci of Drosophila pseudoobscura and $D$. persimilis by different methods. Genetics 87, 743-761.

Corran P. H. and Waley S. G. (1975) The amino acid sequence of rabbit muscle triosephosphate isomerase. Biochem. J. 145, 335-344.

Dayhoff M. O. (1978) Survey of new data and computer methods of analysis. In Atlas of Protein Sequence and
Structure (Edited by Dayhoff M. O.), p. 3. National Biomedical Research Foundation, Silver Spring, MD. Decker R. S. and Mohrenweiser H. W. (1981) Origin of the triosephosphate isomerase isozymes in humans: Genetic evidence for the expression of a single structural locus. Am. J. Hum. Genet. 33, 683-691.

Eber S. W. and Krietsch W. K. G. (1980) The isolation and characterization of the multiple forms of human skeletal muscle triosephosphate isomerase. Biochem. Biophys. Acta. 614, 173-184.

Fielek S. and Mohrenweiser H. W. (1979) Erythrocyte enzyme deficiencies assessed with a miniature centrifugal analyzer. Clin. Chem. 25, 384-388.

Gracy R. W. (1982) Glucosephosphate and triosephosphate isomerases: Significance of isozyme structural differences in evolution, physiology and aging. Isozymes: Curr. Topics Biol. Med. Res. 6, 169-205.

Gracy R. W. and Yuan P. M. (1980) Spontaneous deamidation of two asparagines within the subunit contact sites of human triosephosphate isomerase. Fedn Proc. 39, 1960.

Gibson D. R., Gracy R. W. and Hartman F. C. (1980) Affinity labeling and characterization of the active site histidine of glucosephosphate isomerase--sequence homology with triosephosphate isomerase. J. biol. Chem. 255, 9369-9374.

Hartman F. C. and Gracy R. W. (1973) An active site peptide from human triosephosphate isomerase. Biochem. Biophys. Res. Commun. 52, 388-393.

Hewett-Emmett D.. Venta P. J. and Tashian R. E. (1982) Features of gene structure, organization, and expression that are providing unique insights into molecular evolution and systematics. In Macromolecular Sequences: in Systematic, and Evolutionary Biology (Edited by Goodman M.), pp. 357-405. Plenum. New York

Kahn A., Kaplan J. C. and Dreyfus J. C. (1979) Advances in hereditary red cell anomalies. Hum. Genet. 51, 1-27.

Kester M. V., Phillips T. L. and Gracy R. W. (1977) Changes in glycolytic enzyme levels and isozyme expression in human lymphocytes during blast transformation Arch. Biochem. Biophys. 184, 700-709.

Li W-H. (1982) Evolutionary change of duplicate genes. Isozymes: Curr. Topics Biol. Med. Res. 6, 55-92.

Lu H. S., Talent J. M. and Gracy R. W. (1981) Chemical modification of critical catalytic residues of lysine. arginine and tryptophan in human glucose phosphate isomerase. J. Biol. Chem. 256, 785-793.

Mohrenweiser H. W. (1983) Enzyme deficiency variants: Frequency and potential significance in human populations. Isozymes: Curr. Topics Biol. Med. Res. 10, 5l-68.

Mohrenweiser H. W. and Fielek S. (1982) Elevated frequency of carriers for triosephosphate isomerase deficiency in newborn infants. Pediat. Res. 16, 960-963.

Mohrenweiser H. W. and Neel J. V. (1981) Frequency of thermostability variants: Estimation of total "rare" variant frequency in human populations. Proc. Natl. Acad Sci. USA 78, 5729-5733.

Noltman E. A. (1972) Aldose-ketose isomerases. Enzymes 1 , 271-354.

Neel J. V., Mohrenweiser H. W. and Meisler M. M. (1980a) Rate of spontaneous mutation at human loci encoding protein structure. Proc. Natl. Acad. Sci. USA 77 , 6037-6041

Neel J. V., Satoh C., Hamilton H. B., Otake M., Goriki K., Kageoka T., Fujita M., Neriishi S. and Asakawa J (1980b) Search for mutations affecting protein structure in children of atomic bomb survivors. Preliminary report. Proc. Natl. Acad. Sci. USA 77, 4221-4225.

Omoto K. and Blake N. M. (1972) Distribution of genetic variants of erythrocyte phosphoglycerate kinase (PGK) and phosphohexose isomerase (PHI) among some population groups in Southeast Asia and Oceania. Ann. Hum. Genet. Lond. 36, 61-67. 
Palmieri R. H., Gee D. M. and Noltmann E. A. (1982) Isolation and sequence determination of two pyridoxal 5 -phosphate labeled thermolysin peptides from pig muscle phosphoglucose isomerase. J. biol. Chem. 257, $7965-7968$.

Pullan L. M., Igarashi P. and Noltmann E. A. (1983) Arginine-specific modification of rabbit muscle phosphoglucose isomerase: Differences in the inactivation by phenylglyoxal and butanedione and in the protection by substrate analogs. Archs. Biochem. Biophys. 221, 489-498.

Putman S. J., Coulson A. F. W., Farley T. R. T., Riddleston B. and Knowles J. R. (1972) Specificity and kinetics of triosephosphate isomerase from chicken muscle. Biochem. J. 129, 301-310.

Richkind K. E. and Richkind M. (1978) Polymorphism at the glucosephosphate isomerase locus in the dog. J. Hered. 69, 141-142.

Rogers P. A., Brenton D. P. and Hopkinson D. A. (1980) Changes in the activity and isozyme patterns of glycolytic enzymes during stimulation of normal human lymphocytes with phytohaemagglutin. Ann. Hum. Genet. Lond. 43, 213-226.

Sandberg K. (1973) Phosphohexose isomerase polymorphism in horse erythrocytes. Anim. Blood Groups Biochem. Genet. 4, 79-82.

Satoh C. and Mohrenweiser H. W. (1979) Genetic heterogeneity within an electrophoretic phenotype of phosphoglucose isomerase in a Japanese population. Ann. Hum. Genet. Lond. 42, 283-292.

Singh R. S., Hubby J. L. and Throckmorton L. H. (1975) The study of genic variation by electrophoretic and heat denaturation techniques of the octanol dehydrogenase locus in members of the Drosophila virilis group. Genetics 80, 637-650.

Smith J., Barnes J. K., Kaneko J. J. and Freedland R. A. (1965) Erythrocytic enzymes of various animal species. Nature 205, 298-299.
Smith J. E. and Kiefer S. (1973) Comparative erythrocytes metabolism. Breed differences using canine cells. Enzyme 14, 76-81

Snapka R. N., Sawyer T. H., Barton R. A. and Gracy R. W. (1974) Comparison of the electrophoretic properties of triosephosphate isomerases of various tissue and species. Comp. Biochem. Physiol. 46B, 733-741.

Steinberg M. J. E., Cohen F. E., Taylor W. R. and Feldmann R. J. (1981) Analysis and prediction of structural motifs in the glycolytic enzymes. Phil. Trans. R. Soc. Lond. B. 293, 177-189.

Tashian R. E., Hewett-Emmett D. and Goodman M. (1983) On the evolution and genetics of carbonic anhydrases I, II, and III. Isozymes: Curr. Topics Biol. Med. Res. 7, 79-100.

Thorig G. E. W., Schoone A. A. and Scharloo W. (1975) Variation between electrophoretically identical alleles at the alcohol dehydrogenase locus in Drosophilia melanogaster. Biochem. Genet. 13, 721-731.

Turner T. R., Wade P. T. and Mohrenweiser H. W . (1984) Variation in erythrocyte enzyme activity among primates. Comp. Biochem. Physiol., 77B, 541-545.

VandeBerg J. L. and Stone W. H. (1978) Biochemical genetics of macaques II. Glucose-phosphate isomerase polymorphism in rhesus monkeys. Biochem. Genet. 16, 691-694.

Vives-Corrons J-L., Robinson-Skala H., Mateo M., Estella J., Feliu E. and Dreyfus J-C. (1978) Triosephosphate isomerase deficiency with hemolytic anemia and severe neuromuscular disease. Familial and biochemical studies of a case found in Spain. Hum. Genet. 42, 171-180.

Wheat T. E. and Goldberg E. (1983) Sperm-specific lactate dehydrogenase $\mathrm{C}_{4}$ : Antigenic structure and immunosuppression of fertility. Isozymes: Curr. Topics Biol. Med. Res. 7, 113-130.

Womack J. E. (1982) Linkage of mammalian isozyme loci A comparative approach. Isozymes: Curr. Topics Biol. Med. Res. 6, 207-246. 